In addition the arrangement in several of the chapters, notably in Diseases of the Vessels, and Diseases of the Ovaries, lacks clarity and gives a misleading impression of the relative importance of the various pathological conditions.

\section{THE EMOTIONAL FACTOR IN VISCERAL DISEASE.}

By H. G. McGREGoR, M.D., M.R.C.P. Foreword by R. D. GILleSPIE, M.D., F.R.C.P., D.P.M. Oxford Medical Publications. Humphrey Milford, London, 1938. Pp. 198. Price $8 / 6$.

In recent years medical men have come to interest themselves much more in the relation of mind and body, both in health and disease. Dr. McGregor's book is an introduction in outline to this field of medicine and may fairly be said to mark a milestone in this country.

After a preliminary study of modern views concerning the nature of emotion-a study expressed with a clarity which will be appreciated by all who have attempted to read philosophers on this question-he gives a review of experimental work which shows in detail the results of emotion on digestion. In this, he obviously agrees with most authors and teachers that this is one of the most effective starting points because of the convincing way in which emotion may be shown to affect the alimentary canal, both in common experience and special experiment.

There follow chapters on peptic ulcer, ulcerative colitis and mucous colitis, syndromes of the digestive system which have long been thought to be related, in whole or in part, to chronic emotional states. The inclusion of case histories, mainly from the author's own experience, adds much interest to these chapters.

Subsequent sections of the book deal with respiratory and cardiovascular systems. In each case a summary of relevant experimental work is followed by a discussion of the practical application of these results to the related clinical disorders, in this case, asthma, certain disorders of the action of the heart, and hypertension.

Then come two chapters on the endocrine and autonomic nervous systems, the bodily mechanisms of emotional reaction. Despite our relative ignorance in these fields, the discussion is convincing and effective.

Lastly there is a chapter on diagnosis and treatment which, unlike most, recognises and explains the existence between patient and doctor of a specific and individual emotional situation. If only for this reason, it is a pleasure to read.

Dr. McGregor modestly claims that his book is a first outline of the subject. In his introduction he points to the mechanistic doctrine implicit in so much medical training and illustrates the need for understanding human beings as living organisms, not only in theory but also, and more especially, in practice. Lack of familiarity with known facts concerning the physiology of emotion, and the strange language of the disappearing psychological schools, have undoubtedly prevented the integration into practical medicine of concepts dealing with human beings as complete organisms. In his language and style, Dr. McGregor has successfully evaded the great temptation to save time by the use of technical terms which only confuse those who are new to them.

The difference between acute emotional states on the one hand, and, on the other, the chronic emotional states or " frames of mind " which are the more usual source of the prolonged autonomic and endocrine disturbance leading to obvious clinical disorders is clearly shown, an important point for clinicians. An allied point of view whicho is clearly demonstrated is equally important -emotional tension may exist in an individual without his or her clear recognition of its nature or, sometimes, of its existence.

At the end of each chapter there are lists of references for further reading. Almost the only possible criticism of this book is that these lists seem to contain some rather strange omissions and that the number of mis-spelt names is a little above average.

When one considers the extent to which the two fields of study might contribute to each other, the gap between practical clinical medicine and modern psychological practice is almost incredible. To put an end to this unfortunate state of affairs, calm, clear, clinical discussions, such as those to be found in this book, are of the greatest interest and importance.

\section{COMMON HAPPENINGS IN CHILDHOOD.}

By Sir Frederic Still, K.C.V.O. Oxford University Press. 1938. Price 5/- net.

This small volume will be a delight to al earnest clinicians and not only to those 
whose work for the most part deals with children. As it treats of the problems of everyday and perennial interest, they are just the problems on which one gets such little help from the text-books. This is due, of course, to the fact that for their true appreciation prolonged and sympathetic study is essential, and this is not a characteristic which is exhibited by the author of the average text-book. The profession, therefore, is under a heavy debt of gratitude to Sir Frederic Still for having given so lavishly of his ripe and wide experience.

The questions discussed cover the whole gamut of the fundamental activities and forces in childhood - crying, laughter, temper, tiredness, appetite, fear and sleep, and there is a final and most instructive chapter on the bearing of school life on the health of the child. There can be no doubt that a study of these essays by Sir Frederic cannot fail to arouse a keener and more humane interest in our young patients and at the same time develop a greater ability to deal successfully with their many diseases, functional and organic.

\section{THE BRITISH ENCYCLOP EDIA OF MEDICAL PRACTICE.}

Vol. 9. Mumps to Pneumothorax.

Vol. Io. Poisons legislation to Rosacea.

Edited by Sir Humphry Rolleston, BT.

Butterworth's Medical Publications.

London. 1938. Price 35/- per volume.

These two volumes, which have appeared in rapid succession, complete the list of subjects whose terminology falls within the letters $A$ and $R$ and augur well for an early appearance of the entire encyclopædia.

Vol. 9 includes the discussion of such important subjects as the diseases of the muscles by Dr. Nattrass, myxœdema and diseases of the pituitary gland by Dr. Gardner Hill, nephritis and nephrosis by Dr. Izod Bennett, diseases of the œsophagus by Prof. Grey Turner, diseases of the ovary by Prof. Tohnston, diseases of the pancreas by Mr. Wakeley, diseases of the parathyroid gland by Dr. Donald Hunter, peritonitis in its different aspects by Dr. Lakin, Mr. Zachary Cope and Dr. Kellett, neurosyphilis by Dr. Purdon Martin, pleurisy by the late Dr. Burrell and lobar pneumonia by $\mathrm{Dr}$. R. A. Young. In addition diseases of the nails and certain skin affections fall into this alphabetical section as do also the questions of disputed paternity and of professional negligence.

Vol. 10 embraces, among others, the questions of the legislation of poisons by Mr. Linstead, post-mortem examinations by Dr. Barnard, pregnancy by Prof. Browne, many aspects of psychology including psychological pathology and therapy, radiology in diagnosis and treatment by Drs. Calthrop and Levitt, diseases of the rectum by $\mathrm{Mr}$. Gabriel, the errors of refraction by Mr. Doggart, and the rheumatic infection by Dr. Reginald Miller.

These volumes maintain the high level of excellence, alike in matter, ease of reference, the quality of the illustrations, the clearness of the type and the general appearance, set by their predecessors and reflect great credit on Editor and publishers.

\section{THE CHEMISTRY OF THE STERIDS.}

By HARRY SoBotKa. Baillière, Tindall \& Cox, London. Pp. xiii \& 634. 1938. Price 38/-.

By analogy with the term " lipid " which is frequently used to include the fats and the fat-like lipoids, " sterid " is used here to cover the miscellaneous group of sterols and steroids (or sterol-like substances). This book deals, therefore, with the sterols, the bile acids, the antirachitic vitamins, the cardiac glycosides, the toad poisons, the sex hormones, the hormone or hormones of the adrenal cortex, certain œestrogenic and carcinogenic compounds, and a few substances of related structure. This list alone will suffice to show the wide distribution and the immense physiological and pathological significance of these compounds containing the cyclo-pentenophenanthrene nucleus.

The major portion of the book is concerned with the physical and chemical properties of the sterids and their derivatives; workers engaged in this field will find this catalogue most valuable. The chapter dealing with the methods of structural research will prove of interest to all chemists since it provides a concise account of the methods which have been used to determine the exact structure of the complex sterids. 